\title{
O ROTO NA TELA: O TIPO POPULAR URBANO NO CINEMA CHILENO CLÁSSICO ${ }^{1}$
}

\author{
The roto on the screen: the urban popular type in the classical chilean cinema
}

\section{El roto en la pantalla: el tipo popular urbano en el cine chileno clásico}

\author{
Fabián Núñez \\ Professor adjunto do Departamento de Cinema e Vídeo \\ da Universidade Federal Fluminense (UFF) \\ fabian_nunez@id.uff.br
}

\section{Resumo}

As figuras do roto e do huaso são consideradas tipos populares que encarnam a chilenidade. O pesquisador Santa Cruz Achurra frisa que durante o cinema chileno dos anos 1940 podemos encontrar uma presença maior do huaso em relação ao roto nos filmes. A partir desse dado, nosso objetivo no presente artigo não é buscar respostas para esse fenômeno, mas analisar como a figura do roto se constituiu num importante elemento presente na indústria cultural chilena na primeira metade do século XX e, portanto, foi absorvido pela produção cinematográfica local. Por fim, concentraremos nossos estudos no ator cômico Eugenio Retes, mais especificamente no filme El gran circo Chamorro (1955), dirigido por José Bohr.

Palavras-chave: Roto chileno. Cinema Chileno. Cinema Clássico

\begin{abstract}
The figures of roto and huaso are considered popular types of the chileanity. The researcher Santa Cruz Achurra points out that during the Chilean cinema of the 1940s we can find greater presence of the huaso in relation to the roto on the movies. From this information, our objective in this article is not to seek answers to this phenomenon, but to analyze how the figure of the roto became an important element present in the Chilean cultural industry in the first half on the $20^{\text {th }}$ century, and thus it was absorbed by the local film production. Finally, we will focus our studies on the comic actor Eugenio Retes, specifically in the film El gran circo Chamorro (1955), directed by José Bohr.
\end{abstract}

Keywords: Chilean Roto. Chilean Cinema. Classical Cinema.

\section{Resumen}

Las figuras del roto y del huaso son consideradas tipos populares que encarnan la chilenidad. El investigador Santa Cruz Achurra hace hincapié que durante el cine chileno de los años

\footnotetext{
${ }^{1}$ Este artigo é uma versão do trabalho apresentado no XX Encontro Internacional da SOCINE, que por sua vez é uma pesquisa realizada para a escrita de capítulo de livro sobre musical e cinema latino-americano, organizado pelo prof. Guilherme Maia (UFBA).
} 
1940 podemos encontrar una mayor presencia del huaso en relación al roto en las películas. A partir de esto dato, el objetivo de este artículo no es buscar respuestas a este fenómeno, sino analizar cómo la figura del roto se convirtió en un importante elemento presente en la industria cultural chilena de la primera mitad del siglo XX y, por lo tanto, fue absorbida por la producción cinematográfica local. Por último, el estudio se centrará sobre el actor cómico Eugenio Retes, específicamente en la película El gran circo Chamorro (1955), dirigida por José Bohr.

Palabras clave: Roto Chileno. Cine Chileno. Cine Clásico.

\section{INTRODUÇÃO}

Santa Cruz Achurra (2011), ao estudar a representação do nacional-popular no cinema chileno dos anos 1940, década considerada áurea dessa cinematografia durante o período clássico, constata a diminuição de filmes históricos, gênero comum na produção silenciosa, e o grande sucesso de comédias e melodramas com sequências musicais, em cujos filmes podemos encontrar o protagonismo de personagens populares. Tais filmes abordam tanto o ambiente rural quanto o urbano. Assim, a figura do popular presente nas telas é encarnada sob as duas personagens típicas da chilenidade: o huaso e o roto. Destacam-se entre os principais nomes desse tipo de filmes, os diretores Eugenio de Liguoro, Jorge Coke Délano e José Bohr. Simultaneamente, ao longo da década de 1940, assistimos ao principal esforço para erguer uma indústria cinematográfica nacional, com forte auxílio do Estado: a Chilefilms. Além da construção de estúdios dignos desse termo, vemos a importação de mão de obra técnica e artística, sobretudo da Argentina, e o sonho de alcançar o mercado externo. No entanto, após oito anos de funcionamento e seis de realizações fílmicas, a empresa é definitivamente fechada em 1949 e suas dependências, arrendadas. À guisa de conclusão, Santa Cruz A. sublinha uma presença maior de elementos do campo na produção cinematográfica chilena dos anos 1940, enquanto que, desde a década anterior, o país começava a sofrer um forte êxodo rural em direção aos centros urbanos, além de uma presença maior das camadas populares urbanas no âmbito político, organizados em sindicatos e partidos políticos. Em tom mais de formulação de hipóteses do que de afirmações categóricas, o autor se questiona: "Por que o huaso e não o roto? Para compensar simbolicamente a falta de inclusão dos setores rurais no modelo industrializador? (...) Por que o huaso simbolizava o povo são e bom, infantil e inocente, ainda não envenenado por agitadores? Por que a negação em se reconhecer no urbano e no moderno?” (Santa Cruz A., 2011, p. 137). 
A nossa intenção não é responder a essas questões, pois como o próprio Santa Cruz A. ressalta, seria necessária uma profunda pesquisa para esse empreendimento. No entanto, o nosso estudo tem como ponto de partida essas questões, embora nos foquemos na década seguinte, nos anos 1950, considerado um dos períodos mais turvos da cinematografia chilena em termos de produção, após a derrocada do sonho industrial de Chilefilms. Por outro lado, são anos considerados chaves pela historiografia do cinema chileno, pois é nessa década que surgem as bases de um cinema social e político no âmbito documental. Pela historiografia clássica, é por esse viés que eclode o tão cultuado Nuevo Cine Chileno, a partir da segunda metade dos anos 1960. Portanto, o nosso estudo se volta à figura do roto, uma vez que a nossa preocupação é o universo urbano e como as suas transformações sociais se vinculam com a indústria cultural chilena, sobretudo cinematográfica. Sublinhamos que não podemos esquecer que a sombra do desastre da Chilefilms é um fantasma que ronda a cabeça desses cineastas.

\section{O ROTO: DE OFENSA A SÍMBOLO NACIONAL}

Como frisa Gutiérrez (2008), o roto é, ao lado do huaso, uma "tradição inventada" que, desde meados do século XIX até os dias de hoje, encarna a chilenidade. No entanto, como atenta o autor, apesar de reconhecermos atualmente o seu caráter "inventado", essa atitude desmistificadora não torna essas tradições carentes de potencial simbólico, pois embora forjadas, "tradições inventadas" podem se converter em tradições autênticas. É justamente o caso das figuras do huaso e do roto, que foram fortemente entranhados no imaginário chileno e são, dia a dia, perpetuados em práticas sociais, seja de caráter oficial (como as "Festas Pátrias") ou de caráter mundano, como a indústria cultural. Assim, o que nos interessa não é estabelecer uma gênese do roto e, posteriormente, o seu ingresso na cinematografia chilena, mas apenas pontuar alguns aspectos.

É possível afirmar que o roto é a versão chilena da exaltação do mestiço, do tipo social oriundo da mistura dos povos europeus e ameríndios. Ao longo do século XIX, as intelectualidades latino-americanas se viram incômodas diante do forte avanço das teorias racistas que marcaram esse século. Ávidas por formar nações recém-emancipadas e, por conseguinte, carentes de identidade, as nossas elites precisaram lidar com a miscigenação racial de nossos povos, o que "explicariam" as razões de nosso atraso político, econômico, social e cultural. Frente a esse desafio, foram tomadas medidas simbólicas e físicas para superar os supostos males oriundos de nossa origem racial, em práticas de elevação moral 
(ocultação e repressão às práticas "bárbaras", oriundas dos índios e/ou negros) ou, simplesmente, de branqueamento da população local (pelo incentivo à imigração europeia somado ao extermínio dos povos locais). É inicialmente por esse viés pejorativo que o roto é identificado, i.e., por um habitante urbano de origem popular: um mestiço de hábitos rudes e simplórios, caracterizado por sua vestimenta esfarrapada, o que denota não apenas a sua precariedade material, mas também (e sobretudo) a carência de "modos civilizados", espelhada em seu aspecto desleixado e sujo. Como aponta Gutiérrez (2008), alguns intelectuais buscaram a origem do roto chileno em tempos coloniais, nos relatos da Conquista, inclusive no próprio Pedro de Valdivia. Assim, os espanhóis que se fixaram no Chile, devido à dureza da terra e ao constante embate contra os belicosos nativos (os Araucanos), tinham as suas vestes rasgadas, o que deu a (má) fama aos chilenos de rotos por parte dos habitantes do Peru, sede do vice-reino e terra rica e próspera. $^{2}$ Nesse caso, trata-se da busca de uma genealogia "nobre" ao roto, o que já caracteriza a ação de parte da intelligentsia chilena no século XX. Assim, de ofensa, o roto se converte em elemento característico do povo chileno, sob o ônus, como frisa Gutiérrez, da mistificação da mestiçagem como aspecto fundador da identidade nacional do Chile. Portanto, sob o ensejo da militância estética das vanguardas artísticas dos anos 1920, seguido pelos movimentos regionalistas e neocriollistas das décadas posteriores, a mestiçagem, o hibridismo e o multiculturalismo são alçados à marca distintiva das identidades nacionais da América Latina.

Gutiérrez (2008) expõe como o "racismo científico" oitocentista é reprocessado no início do século seguinte, especialmente, pela monumental obra do médico e ensaísta Nicolás Palacios, intitulada Raza chilena, publicada em 1904. Não detalharemos aqui o percurso estudado por Gutiérrez, mas o importante é notar que para Palacios, a miscigenação racial que formou o povo chileno não é um fator de degenerescência, pelo contrário, seria o aspectochave da superioridade chilena. É por isso que Gutiérrez frisa que o nacionalismo de Palacios, somado ao seu apreço pelas camadas populares de seu país, resulta na exaltação racial do mestiço chileno. Gutiérrez também cita que é seguindo por esse caminho que outros autores da primeira metade do século XX, como Roberto Hernández e Luis Durand, exaltam o roto como o representante autêntico do povo chileno, ao buscar as manifestações de sua magnanimidade, sobretudo nas heroicas ações das camadas populares pela defesa da Pátria, durante as Guerras de Independência (1813-1826), contra a Confederação Peru-Boliviana

\footnotetext{
2 É impossível não identificarmos a rivalidade nacionalista entre chilenos e peruanos no "mito de origem do roto", sobretudo no ato simbólico de transformar um suposto insulto dos peruanos aos habitantes do Chile em motivo de orgulho, de símbolo nacional.
} 
(1836-1839) e do Pacífico (1879-1883). Assim, podemos afirmar que o roto é caracterizado como um tipo popular, uma pessoa humilde, ingênua, bem-humorada e brincalhona, mas que não se isenta ao ser chamado pelo dever, sendo capaz de atos de bravura, movido por sua índole altruísta. É sob esse olhar glorioso que o roto foi literalmente monumentalizado, quando em outubro de 1888 é inaugurado o Monumento ao Roto Chileno, localizado na Praça Yungay, em Santiago. Concebido e executado pelo escultor Virginio Arias, o monumento é um arco de pedra em cujo cume se encontra a estátua de um jovem em mangas de camisa, peito semidescoberto, pés descalços e munido com um rifle na mão direita. Simbolicamente representa o soldado desconhecido caído nas lutas pelo país, mais especificamente, durante a Guerra contra a Confederação Peru-Boliviana, uma vez que a praça (e o bairro) é batizada de Yungay em homenagem à batalha que consolida a vitória chilena ocorrida em 20 de janeiro de 1839. Em 1888, ano da inauguração do monumento, é instituída a data de 20 de janeiro como o "Dia do Roto Chileno", oficialmente comemorado até hoje na referida praça com a deposição de flores por autoridades civis e militares e a execução do Hino de Yungay, composto em 1839, dois meses após a batalha, para comemorar a vitória e que foi, durante boa parte do século XIX, considerado um segundo hino nacional chileno, devido à sua ampla popularidade.

Santa Cruz A. (2008) identifica nos filmes históricos do cinema silencioso chileno a presença dessa face do roto. Portanto, é o roto patriota que é digno de estar presente nas telas nacionais, i.e, o personagem popular que combate e morre anonimamente pelo país e não o roto alzado, "insolente e rebelde, que questiona ou resiste (...), figura que, na virada do século, se associou à ação do agitador estrangeiro" (SANTA CRUZ A., 2008, p. 60). Por sua vez, Gutiérrez (2008) chama a atenção de que o elogio ao roto por parte dos intelectuais no começo do século XX se refere a um momento do passado, como um tipo popular em extinção, o que pressupõe que a classe trabalhadora chilena perdeu (ou estava perdendo) o seu caráter singelo, bonachão, valoroso e ordeiro. Portanto, de ofensa a símbolo nacional, a figura maltrapilha do roto chileno jamais foi uma unanimidade entre a intelligentsia nacional, pois um tom pejorativo sempre o espreita. Nesse sentido, é bastante diverso em relação à figura do huaso, considerado sem controvérsias como um símbolo positivo de chilenidade, como frisa Gutiérrez. Assim, os debates em torno do huaso e do roto manifestam o clássico embate entre cidade e campo, que tanto fremiram as discussões nacionalistas nos séculos XIX e XX na América Latina, tradicionalmente associando o universo rural com o repositório puro das idiossincrasias autenticamente nacionais. É por esse viés que podemos entender, por exemplo, 
as reflexões do escritor Joaquín Edwards Bello em sua obra El roto, publicada em 1920. Sob a influência do Naturalismo, o livro retrata o bas-fonds da sociedade santiaguina, formado por uma horda de miseráveis, expulsos do campo, que se aglomeram no sórdido bairro surgido atrás da Estação Central. Essas pessoas, que demonstravam o seu valor e empenho na labuta diária nas fazendas, se convertem em uma massa ignota e andrajosa, habitando os ambientes insalubres e prostibulares da capital, transformando-se em seres infra-humanos, vítimas da fome, do álcool e do infortúnio. Assim, a origem racial, degenerada ou gloriosa, pouco importa, mas, sim, a degradação provocada pelo meio, resultado do êxodo rural. Portanto, para entendermos o que subjaz nos debates em torno do roto é necessário compreender não apenas as opiniões políticas e as matizes ideológicas dos autores que se debruçaram sobre o tema, mas também entendermos as transformações sociais e políticas ocorridas no Chile ao longo do século passado.

\section{O ROTO NA INDÚSTRIA CULTURAL CHILENA: DA IMPRENSA E DOS PALCOS PARA AS TELAS}

Em seu estudo, Salinas Campos (2006) frisa o quanto o teatro cômico chileno - e, por extensão, o imaginário popular no qual se encontra inserido - era tratado com profundo desprezo pelas elites sociais e intelectuais chilenas, ao encararem tais produções dessa indústria cultural como um mero entretenimento vulgar e imoral. Uma das vítimas desse desprezo é o personagem fictício Juan Verdejo, uma das principais representações do roto na indústria cultural nacional. Verdejo surge nas páginas da revista de humor político Topaze, periódico semanal editado em Santiago, a partir de 1931, que foi concebido pelo jornalista, desenhista e cineasta Jorge Coke Délano. Publicada até 1970, Topaze adquiriu ampla popularidade e foi uma escola de várias gerações de jornalistas e desenhistas. Segundo Rueda (2011), o roto Juan Verdejo é publicado pela primeira vez na edição $\mathrm{n}^{\circ} 11$, desenhado pelo próprio Délano e com versos do poeta popular Héctor Meléndez. Trata-se de um tipo magro, desdentado, barba por fazer, cabelo desgrenhado, chapéu disforme e furado, com as roupas rasgadas e os pés descalços. Vários desenhistas da revista o retrataram e, por isso, possui distintos traços. No entanto, é imediatamente reconhecido não apenas por seu aspecto físico, mas também por sua simpatia e expressões mordazes. Como analisa Salinas Campos (2006) em seus estudos, o roto encarnado por Verdejo deita raízes a uma vasta tradição satírica de tom social e político que existe na imprensa chilena desde tempos coloniais, oriunda do 
universo picaresco tão fortemente entranhado no imaginário espanhol. Desse modo, essa faceta do roto chileno é uma versão criolla do pícaro, devidamente (sub)urbanizado, sendo possível aproximá-lo então das figuras do pelao (ou pelado) mexicano e do golfo espanhol.

Devido ao seu imenso sucesso, Juan Verdejo migra para os palcos. No começo de 1938, a Companhia Bataclánica Cóndor, uma das mais importantes do meio artístico cômico nacional, apresenta a "jocosa revista” Juan Verdejo, mundo arriba, de autoria de Eugenio Retes, a partir de um tema do poeta e dramaturgo Víctor Domingo Silva. Trata-se de um espetáculo, formado por dez quadros e variedades, que entra em cartaz no imponente Teatro Politeama, atrás do Portal Edwards e próximo à Estação Central, região de agitada vida boêmia naqueles tempos. A companhia em questão, criada em 1934, foi a mais célebre desse estilo nos anos 1930 e totalmente voltada para o riso popular. Conforme Salinas Campos (2006), desde a sua fundação, manteve as suas atividades de modo ininterrupto até por volta de 1941. Ocupava o Teatro Balmaceda, na margem norte do rio Mapocho, na interseção dos bairros Recoleta e Independencia, região popularmente conhecida, desde tempos coloniais, de La Chimba, setor celebrizado, desde o final do século XIX, por ser um local de diversão popular. Logo em seguida, o famoso roto surge nas telas de cinema no média-metragem Lo que Verdejo se llevó (1941), dirigido por Eugenio de Liguoro, e nos longas Verdejo gasta un millón (1941), também de Liguoro, e Verdejo gobierna en Villaflor (1942), dirigido por Pablo Petrowitsch. Os dois longas são corroteirizados e os três filmes protagonizados por Eugenio Retes. Teria sido o então produtor Petrowitsch quem teria convencido o comediante Retes a interpretar Verdejo nas telas, transformando Verdejo gasta un millón em uma das maiores bilheterias do cinema chileno nos profícuos anos 1940. Em 1942, Liguoro compra os estúdios Santa Elena, fundados por Délano, e no entusiasmo do êxito de Verdejo, leva adiante a saga do roto. No entanto, o segundo longa não foi bem recebido pelo público, terminando a carreira cinematográfica de Verdejo. ${ }^{3}$ Ressaltamos que Liguoro se destaca por esses anos por trazer ao cinema as principais estrelas cômicas dos palcos chilenos, como também são os casos de Lucho Córdoba e Ana González. Aliás, o longa seguinte protagonizado por Retes, após os filmes de Verdejo, é Dos caídos de la luna (1945), também dirigido por Liguoro, no qual compartilha o estrelato com Ana González, conhecida por sua personagem radiofônica Desideria, uma empregada doméstica, que apesar de sua origem humilde, é mordaz com os arraigados preconceitos sociais e raciais de seus patrões (ela se diz ser a presidente da

\footnotetext{
${ }^{3}$ Délano levaria a sua criação ao cinema muito tempo depois ao dirigir o curta institucional El imponente señor Verdejo (1957), também protagonizado por Retes.
} 
CONADECAPA - Corporação Nacional das Empregadas de Casa Particular). Logo, podemos afirmar que Desideria é uma versão feminina do roto e Liguoro soube tirar proveito ao levar para as telas os dois principais atores cômicos especializados em tais tipos populares.

Eugenio Retes, de origem peruana e oriundo de uma família de artistas, é um dos principais nomes da comédia chilena a partir dos anos 1930. Antes de fazer sucesso com Juan Verdejo, Retes já havia atuado no palco do Teatro Politeama, em 1938, com a revista criolla intitulada De Renca al Crillón e a obra Acá en el rancho chico, satirizando o fenomenal êxito cinematográfico mexicano Allá en el rancho grande (1936), de Fernando de Fuentes. Pelas informações de Salinas Campos, a peça de Retes era composta por "contrapuntos, tonadas e duelos de guitarras entre charros mexicanos e rotos chilenos" (Idem, p. 3), chegando a ter quarenta e cinco artistas em cena. Por volta desse período, ingressa na Companhia Bataclánica Cóndor, dirigida por seu irmão Rogel Retes.

O nosso objetivo não é realizar um estudo sobre a interrelação entre a imprensa e o teatro de revistas e a produção cinematográfica no Chile. Deveríamos incluir também nesse repertório a rádio e a indústria fonográfica. Portanto, a produção cinematográfica chilena em seu chamado período clássico não é muito diferente de outras cinematografias latinoamericanas. Também é semelhante a forte rejeição, por parte da elite intelectual e social, às produções locais de êxito comercial. Nesse sentido, é impressionante a radical diferença entre as pretensiosas obras da Chilefilms e essa produção de apelo popular. E o próprio cinema chileno produziu verdadeiras pérolas ao ironizar o erudito e o popular no cinema e também abordar a indústria cinematográfica (e, por extensão, cultural) como uma fábrica de ilusões, além de satirizar as relações entre centro e periferia ao retratar com humor e inteligência as dificuldades da produção fílmica local diante dos modelos hegemônicos (hollywoodianos ou das indústrias latinas, como Argentina e México). Destacamos nesse rol, as comédias Hollywood es así (1944), de Jorge Délano, e La dama de las camelias (1947), de José Bohr. ${ }^{4}$ No entanto, nossos olhos se voltam para a década seguinte, quando o sonho industrial da Chilefilms se transforma em um pesadelo devido ao seu fracasso. Assim, a década de 1950 foi retratada pela historiografia clássica do cinema chileno como um período sombrio, preocupando-se mais em vislumbrar o que irá eclodir na década seguinte do que compreender a sua singularidade. Portanto, cremos que esse período merece pesquisas e análises mais aprofundadas, o que o presente texto, com certeza, não dará conta.

\footnotetext{
${ }^{4}$ Sobre La dama de las camelias, indicamos o texto de Santa Cruz G. (2011) e o artigo de Melo (2016, p. 235244).
} 


\section{EL GRAN CIRCO CHAMORRO: O ROTO COMO UM SÍMBOLO NACIONAL AUTOCONSCIENTE}

A comédia El gran circo Chamorro (1955) narra a obstinação de um roto em enfrentar a vida, como um legítimo representante do valor do povo chileno. Eurípedes Chamorro (Eugenio Retes) é um palhaço e "pau-pra-toda-obra” no circo do qual é o dono, herança de um velho amigo. Envia seu suado dinheiro para Santiago, com o propósito de pagar os estudos em Medicina de seu filho Fernando (Pepe Guixé). No entanto, ao ir para a capital, descobre que o filho havia abandonado a universidade e gastou o dinheiro com uma devastadora paixão. Após retornar com Fernando, descobre que o seu circo tinha sido indevidamente apropriado, graças a documentos falsos. Diante de tantas adversidades, Chamorro não se abate e decide reconstruir a sua vida a partir do zero, realizando vários trabalhos. A sequência de abertura do filme já propõe Chamorro como esse roto que simboliza todo um povo. São planos dos Andes e a voz over do próprio diretor, em tom bastante autoral, que se dirige ao público: "Meus amigos, lhes fala José Bohr. Enquanto admiram a beleza extraordinária da Cordilheira dos Andes que, com suas neves eternas, é como um largo sorriso que saúda ao viajante. Sorriso que também parece se refletir no caráter sempre otimista de um povo: o povo chileno. Neste povo sem igual, encontrei-o sob a humilde tenda de um desses circos que se anunciam sempre sob o nome pomposo de 'o Grande Circo..."”. No entanto, esse prelúdio não é o único momento metanarrativo em um filme supostamente tão convencional. Logo após a abertura, os créditos do filme são curiosa e inventivamente apresentados diegeticamente, como se fossem anúncios do circo. Além disso, em mais de uma ocasião, Chamorro, diante de uma inesperada situação, afirma que tais coisas “parecem como nos filmes”. Como analisa Santa Cruz Grau (2011), essas expressões denotam que são coisas improváveis, maravilhosas, tais como no cinema. O ápice é quando o personagem exclama de tal modo, olhando sorridentemente para a câmera, desmontando o artifício. Como o próprio Santa Cruz G. sublinha, o uso de tais procedimentos metanarrativos é sabiamente justificado pelo próprio tema-título do filme, o circo, que expressa exatamente o sentido de espetáculo, entretenimento, deslumbramento e, ao mesmo tempo, artificialidade.

O objetivo do estudo de Santa Cruz G. (2011), ao analisar os filmes La dama de las camelias e El gran circo Chamorro, é chamar a atenção para a "invisibilidade" sofrida por José Bohr na historiografia tradicional do cinema chileno. Tais estudos se centraram no Nuevo 
Cine Chileno, na virada dos anos 1960/70, e reproduzem o discurso de seus cineastas de ruptura com a produção cinematográfica das décadas anteriores. Assim, segundo Santa Cruz G., ao estudar os dois filmes mais célebres dirigidos por Bohr, o cinema chileno moderno não compreendeu determinadas operações formais do diretor teuto-chileno em questão, ocasionando um apagamento de seu nome, ao entender boa parte da produção cinematográfica chilena até meados dos anos 1960 como ideologicamente reacionária. De fato, é possível interpretar tais filmes sob esse viés, mas o atual esforço da revisão historiográfica é entender as singularidades dessa produção, o que significa romper com uma grade interpretativa consolidada, até então, pelos estudos sobre cinema. Assim, rompe-se com um tipo de leitura que põe um conjunto bastante diverso de filmes e cineastas sob um mesmo prisma. Por outro lado, ainda que seja sob determinadas regras de gêneros narrativos e um questionável espectro ideológico, será que, de fato, esses filmes estão realmente tão distantes da representação do dia a dia de certos setores sociais do Chile de sua época? Essa não é a questão-chave de Santa Cruz G., mas, sim, a ambiguidade e a autorreflexividade presentes em La dama de las camelias e em El gran circo Chamorro, procedimentos formais considerados como típicos do cinema moderno. Portanto, essas duas comédias dirigidas por Bohr, uma dos anos 1940 e a outra da década de 1950, nos chamam a atenção não somente pela qualidade técnica, mas, sobretudo, pela ousadia narrativa e estética. Em suma, não se trata de filmes "menores", ingênuos, embora tenham sido assim considerados, até então, pela historiografia.

Além da narração de abertura, na qual Bohr explicitamente apresenta o seu personagem-título como um símbolo nacional-popular, há outras sequências que reforçam a proposta do filme. É o caso da sequência musical estrelada pela cantora cubana Xiomara Alfaro. A aparição de Alfaro no filme de Bohr se deve ao senso de oportunidade do cineasta: a cantora caribenha se encontrava no Chile em uma turnê. Assim, nessa sequência, Alfaro aparece em um salão decorado com bandeiras chilenas cantando a guaracha Atrácale el bote, composta pelo próprio cineasta. O ambiente é o palco de uma casa de espetáculos chamada “El Pollo Dopado", uma piada com a célebre boate El Pollo Dorado, localizada próximo à Plaza de Armas e ao Palácio de La Moneda, e que se converteu na principal casa noturna de ritmos nacionais nos anos 1950, se referindo a si mesma como o "rincón de la chilenidad". Por esse motivo, entendemos os temas nacionais na decoração do salão e a letra da música, que se refere a uma mulher que chega ao Chile em busca do amor. Porém, o instigante é a presença de uma cantora e um ritmo musical de Cuba. A guaracha é um gênero popular cubano caracterizado por suas letras satíricas. Nada mais conveniente para um roto. Em 
Atrácale el bote, a música, em determinado momento, se converte em uma paródia de Cielito lindo, a famosíssima canção tradicional mexicana. Assim, essa sequência musical se converte numa verdadeira mistura de latinidades, além de literalmente brincar com o nacional e o estrangeiro, sob o viés do popular. Frisamos que a música é tocada mais uma vez no filme, após Chamorro flertar com a "empregada boazuda" da casa em que vai trabalhar como encerador de pisos. É uma ponta interpretada pela atriz cômica Iris del Valle, que havia migrado da rádio para o cinema pelas mãos de Bohr em 1948 e já tinha atuado ao lado dos irmãos Retes no teatro de revista, no final da década de 1930. Nos anos 1950, era vedete da Companhia de Revista Bim Bam Bum, que sacudiu as noites de Santiago nessa década. No filme em questão, Chamorro dá algumas investidas infrutíferas à empregada, terminando por desistir com uma expressão de duplo sentido e, assim, dar início à sua árdua labuta de encerar o piso. No entanto, ao escutar no rádio Atrácale el bote, o jogo se inverte, uma vez que é a empregada boazuda que passa a flertar com o palhaço. Assim, se dá o mote para uma curta sequência de dança entre os dois, o que, obviamente, causa uma gag visual que é o bailado de Retes, culminando no "gingado" acelerado do personagem, que termina com ele, encerando o chão em velocidade rápida acompanhado de um inusitado som cômico de realejo. A sequência termina abruptamente com o plano de um estouro de garrafa de champanhe, fazendo assim o raccord para a sequência da festa na mansão sob uma evidente metáfora visual de caráter sexual. Para finalizar a análise da guaracha, frisamos que Cielito lindo recebe uma versão chilena nas eleições presidenciais de 1920, criada pelos partidários de Arturo Alessandri Palma, que ganha o pleito. Essas eleições são consideradas pela historiografia chilena a débâcle da república oligárquica, quando a crise do modelo agroexportador se expressa politicamente com a chegada ao poder da burguesia com o apoio das camadas médias e populares urbanas, por intermédio da figura política chilena mais importante do começo do século XX. Assim, ao som de uma guaracha, que evoca a vitória sobre a tradicional elite agrária, o roto dança na sala de estar da alta burguesia, que está sendo preparada para uma festa à qual não fora convidado.

O tema da mobilidade social se expressa pelo viés geracional. Todo o esforço (e orgulho) de Chamorro é ver o seu filho em outro patamar social, cuja oportunidade virá pelos estudos, o que a vida negou ao velho palhaço. Apesar das boas notas, o que demonstra empenho e talento, Fernando é um personagem frágil, talvez devido à desatenção afetiva de seu pai, às voltas com a labuta diária. No entanto, o compromisso de Margarita (Malú Gatica), a filha do patrão, com Fernando é posto em causa por Chamorro, ao constatar que ele e seu 
filho não pertencem àquele mundo, uma vez que os ricos da festa são zombeteiros e preconceituosos. Porém, no final, Chamorro, que é acima de tudo um sujeito de bom coração (como todo roto), aprova a relação entre os dois, ao notar a sinceridade dos sentimentos de Margarita em relação ao seu filho. A mesma nobreza encontramos no pai de Margarita, que aprova o amor da filha, apesar da diferença de classe. Assim, a ascensão social é marcada pela concórdia entre as classes, que se dá por meio do amor e do trabalho, sob o esteio da sinceridade. Essa conciliação social pode ser lida como mais um aspecto da nobreza encarnada pelo roto, dando sintonia entre povo e nação. No filme, a síntese desse orgulho nacional, além do otimismo do roto frente às adversidades da vida, é expressa na tonada, ritmo folclórico nacional, intitulado Soy chileno. No período durante o qual Chamorro é dono e motorista de ônibus, uma das personagens entra em trabalho de parto no meio da estrada. Imediatamente, o velho Chamorro ordena o seu filho Fernando a cumprir o seu dever de médico. Ele inicialmente titubeia, pois, de fato, não é médico, mas para Chamorro pai, os estudos somados com a vocação são o fundamental, posto à prova em uma situação de emergência. Diante do mandato do pai - "Cumpra com sua obrigação, Dr. Chamorro!” -, Fernando, apesar de sua incerteza, se sente no dever moral de acudir à parturiente e realiza o parto com sucesso, com a ajuda do pai e de outros passageiros. Ao terminar, sai do ônibus e, diante do feliz e orgulhoso cumprimento de seu pai, que o chama - de novo - de "Doutor Chamorro", Fernando olha para as suas próprias mãos e altivamente repete as palavras de seu pai: "Doutor Chamorro". Assim, as dúvidas de Fernando em relação à sua competência como médico são dissipadas graças ao senso de dever e à confiança do velho palhaço. Podemos entender esse ato como mais um sinal da honradez e otimismo do roto. Em continuação, a sequência aprofunda essa leitura ao engatar com o número musical de forte tom patriótico, com a canção Soy chileno. Assim, é com essa música que Chamorro continua a viagem no volante do ônibus, onde dá as boas-vindas a mais um chileno que acabara de chegar ao mundo. Chamorro diz que o menino recém-nascido é "mais chileno que todos os chilenos, pois nasceu em pleno campo chileno". Mais uma vez, vemos a exaltação do universo rural como o autêntico repositório das idiossincrasias nacionais, curiosa e sintomaticamente dito pela boca de um roto. A sequência exibe planos da Cordilheira e cenas campestres, com os passageiros do ônibus e os transeuntes na estrada, fazendo coro ao refrão entoado por Chamorro. Interessante notar que um dos personagens do ônibus é um turco - no típico estereótipo de comerciante -, que não se furta em afirmar que ele "também é chileno". Logo, podemos entender que para além de questões meramente geográficas, a chilenidade é 
entendida no filme quase que como um conjunto de valores, marcado principalmente pelo otimismo diante da vida, que é posto em prática pelo roto, por mais que ele reconheça que o campo chileno é literalmente o berço desses princípios ideológicos. ${ }^{5}$ Aliás, não podemos deixar de citar que no longa anterior de Bohr, intitulado Uno que ha sido marino (1951), também protagonizado por Retes, há a canção Santa Lucía, que exalta o cerro cartão postal, onde foi fundada a cidade de Santiago. Assim, podemos notar que em ambos filmes há uma música de louvor pátrio. Santa Cruz G. sublinha que El gran circo Chamorro é um filme "redescoberto" nos anos 1990, ao ser exibido periodicamente na televisão chilena, especialmente durante as "Festas Pátrias" (os festejos pela Independência do país). Passados quarenta anos, o filme é tratado pela indústria cultural televisiva como a cristalização da nacionalidade, ao qual se soma o gosto que o mundo contemporâneo possui pelas obras do passado, em especial as dos anos 1950, conferindo-lhe um ar de tempos de ingenuidade e simplicidade. Portanto, podemos afirmar que o roto patriota continua, de certa forma, a dar as caras nas telas. Em sua leitura, Santa Cruz A. interpreta a picardia do roto dos filmes de Bohr como "a imagem do popular subordinado, mas simpático, ainda que posto nos marcos do urbano e do moderno, sem abandonar o fundamental da matriz identitária conservadora" (SANTA CRUZ A., 2008, p. 63). Algo bastante distinto da figura de Juan Verdejo presente em Topaze, como também assinala Santa Cruz A. (2011), um popular que questionava a classe política chilena. Do mesmo modo como elogia a Ana González e, especialmente, a sua personagem Desideria, em seu discurso profundamente crítico aos aspectos sociais do país. Assim, podemos concluir que Santa Cruz A. não descarta plenamente o caráter subversivo do roto e, menos ainda, um aspecto político que a comédia possa adquirir. Aliás, ao mencionarmos a personagem de Desideria, não podemos deixar de mencionar que a figura interpretada por González nos faz lembrar a célebre personagem, também de origem radiofônica e posteriormente migrada para o cinema, de Cándida, protagonizada pela atriz argentina Niní Marshall. Cremos que um estudo comparativo entre Desideria e Cándida, e, portanto, entre González e Marshall, merece ser realizado. Assim como é promissor pensar em outras análises comparativas em relação a outras personagens de empregadas domésticas no cinema latino-americano, por exemplo, as encarnadas por Zezé Macedo ou Dercy Gonçalves nas chanchadas brasileiras ou na personagem da Índia Maria, interpretada por María Elena Velasco, no cinema popular mexicano, a partir dos anos 1970. Esse rol de

\footnotetext{
${ }^{5}$ Como curiosidade, frisamos que a nacionalidade chilena segue o princípio jurídico da consanguinidade (jus sanguinis), conciliado pelo princípio da territorialidade (jus solis).
} 
personagens em várias cinematografias latino-americanas chama a atenção em como a figura da empregada doméstica em comédias pode ser uma chave para interpretar a modernização conservadora de nossos países. ${ }^{6}$

É pelo viés da crítica social pela comédia que podemos aproximar a análise da figura do roto com o estudo da chamada "cantinflada", o linguajar verborrágico de Cantinflas, estudado por Bragança (2003). Oriundo do teatro de variedades e dos espetáculos circenses, Mario Moreno (Cantinflas), migra para as telas esse humor picaresco surgido nos arrabaldes de uma Cidade do México em plena expansão, sob o ensejo do projeto modernizador do Estado pós-revolucionário mexicano. Como frisa Bragança, Cantinflas é um peladito, personagem do folclore urbano mexicano, uma figura da periferia da Cidade do México, socialmente excluído, de um falar grosseiro e popularesco. No entanto, assinala Bragança, "Cantinflas apresenta um peladito mais cômico, mais burlesco, menos agressivo, mas não menos inquieto e incômodo". Acreditamos que esta seja uma chave para estudarmos a figura do roto no cinema chileno. Bragança chama a atenção que durante os preparativos da Copa do Mundo de 1986, um desenho de Cantinflas jogador de futebol foi proposto como mascote do evento. No entanto, iniciou-se um debate sobre a impropriedade de um pelao, um pária social, representar a Nação mexicana. Assim, apesar de Cantinflas ser uma figura de amplo reconhecimento internacional, o aspecto considerado deletério do pelao acabou por prevalecer, ocasionando a escolha como mascote da Copa uma pimenta com sombrero e fartos bigodes, uma figura mais simpática e consensual da mexicanidade. Por sua vez, o roto chileno é muito mais ambíguo, pois apesar de também possuir esse caráter pejorativo, como assinala Gutiérrez (2008), e por isso, o consenso em torno da figura do huaso como o símbolo positivo de chilenidade ${ }^{7}$; o roto é uma figura que adquiriu um caráter oficial, uma vez que há um monumento e uma data comemorativa reservada a ele. Nesse sentido, apesar de os governos pós-revolucionários mexicanos terem incorporado elementos populares para a criação da identidade nacional mexicana, o pelao não foi assimilado pelo discurso do nacionalismo revolucionário. Curiosamente, o roto foi processado pelo Estado chileno, em

\footnotetext{
${ }^{6}$ Relembramos que o presente artigo é uma versão do trabalho apresentado no XX Encontro Internacional da SOCINE, no Seminário Temático "Cinema e América Latina: debates estético-historiográficos e culturais". Na ocasião, a personagem Desideria suscitou vivo interesse. Agradecemos as sugestões apresentadas acima e acreditamos que esse é um tema que merece mais estudos.

${ }^{7}$ É instigante pensar que nas cerimônias oficiais pelo Dia do Roto Chileno, além das honras militares, também são comumente realizadas na Praça Yungay apresentações de cueca - a dança típica chilena - por grupos folclóricos vestidos de huasos e chinas (a versão feminina do huaso).
} 
nome de um discurso de exaltação patriótica às classes populares. Por isso, afirmamos que o roto é uma figura que possui uma profunda ambiguidade, o que o torna fascinante. ${ }^{8}$

\section{CONSIDERAÇÕES FINAIS}

Recentemente, estudiosos buscam rever aspectos que foram entronizados na historiografia do cinema chileno, que, movido pela monumentalização do Nuevo Cine Chileno, destroçou criticamente obras de fecundos cineastas, associados, portanto, a um cinema "malfeito" e "alienante". É o caso de José Bohr. Suas comédias foram tradicionalmente interpretadas como filmes sem nenhum valor na cinematografia chilena. Assim, as duplas de estudiosos Cavallo e Díaz (2007) e Cortínez e Engelbert (2014) buscam desmontar esses argumentos ao frisar, por exemplo, que Bohr possui uma vasta carreira cinematográfica, que inclui filmes no México e em Hollywood. Assim, esses autores chamam a atenção de que Bohr conhece muito bem o seu ofício e que é um dos raríssimos estrangeiros, ao lado de Buñuel, por exemplo, a ser aceito no restrito sindicato de trabalhadores artísticos do cinema mexicano. Em suma, é possível condenar os filmes de Bohr no nível político-ideológico, mas não em termos técnicos e profissionais. Além disso, Bohr possuía um talento artístico versátil, já que também transitava pelo teatro de revista e pela rádio, como ator, cantor e compositor, não somente no Chile.

Frisamos que nos anos 1960, Eugenio Retes já não reina sozinho como o principal ator cômico do cinema chileno. Destaca-se outro ator, que, apesar de aparecer nas telas desde meados dos anos 1940, alcança o seu auge no cinema chileno duas décadas depois: Manolo González. Oriundo da rádio e do teatro de revista, González é conhecido por seu humor político em alfinetar os problemas cotidianos enfrentados pelo cidadão urbano comum. Como frisam Cavallo e Díaz (2007, p. 51), caracterizado por seu terno e chapéu fedora, González representa um upgrade ao seu antecessor, o roto Verdejo. Segundo os autores, enquanto Verdejo encarna o (lumpem)proletariado oriundo do êxodo rural, González já é um homem da cidade, tipicamente identificado com a classe média urbana, preocupada com os problemas da metrópole e às voltas com o arrivismo social. Coube aos cineastas Bohr e Tito Davison, esse

\footnotetext{
${ }^{8}$ É possível afirmar que o lado deletério do roto se destaca totalmente do aspecto patriótico na figura do guachaca. Chilenismo de origem quéchua, o termo se refere a pessoas vulgares, de origem humilde, ou alguém que bebe muito. Desde os anos 1990, há um movimento de reivindicação de chilenidade a essa figura por parte de movimentos culturais e folclóricos, o que inclui concursos de rei e rainha guachaca, premiando personalidades consideradas próximas ao povo.
} 
“ciclo Manolo González” nos anos 1960, colocando ao lado do comediante a presença de outros cômicos e artistas locais (entre eles, Retes).

Por outro lado, podemos interpretar que o roto tende a se apresentar no cinema chileno a partir dos anos 1960 sob a figura do favelado, do alcoólatra pobre e da criança de rua. Do mesmo modo, podemos reconhecer a sua picardia no retrato das classes médias baixas, na figura do suburbano ou do provinciano - curiosamente, nos cineastas mais experimentais, i.e., Raúl Ruiz e Cristián Sánchez. Postulamos que é sob essas duas facetas, a do suburbano e do provinciano, que o roto continua a se manifestar na cinematografia chilena contemporânea. Assim, é por essa chave que podemos ler alguns personagens presentes em comédias como $E l$ chacotero sentimental - la película (1999) de Cristián Galaz, Taxi para tres (2001) de Orlando Lübbert, Negocio redondo (2001) de Ricardo Carrasco, Sexo con amor (2003) de Boris Quercia, Che Kopete - la película (2007), de León Errazuriz, Fuerzas especiales (2014) de José Miguel Zuñiga, entre outros. Devemos lembrar que o roto também se encontra presente na televisão e na publicidade. Em suma, o roto continua a dar à sua cara nas telas e, por extensão, na indústria cultural chilena.

\section{REFERÊNCIAS}

BRAGANÇA, Maurício de. Cantinflas e Mazzaropi: um peladito e um caipira no descompasso do bolero e do samba. 2003. 142f. Dissertação (Mestrado em Comunicação, Imagem e Informação) Instituto de Arte e Comunicação Social, Universidade Federal Fluminense, Niterói, 2003.

CAVALLO, Ascanio; DÍAZ, Carolina. Explotados y benditos: mito y desmitificación del cine chileno de los 60. Santiago: Uqbar, 2007.

CORTÍNEZ, Verónica; ENGELBERT, Manfred. Evolución en libertad: el cine chileno de fines de los sesenta. Santiago: Cuarto Propio, 2014.

GUTIÉRREZ, Horacio. Exaltação do mestiço: a invenção do roto chileno. Esboços - Revista do Programa de Pós-Graduação em História da UFSC. Florianópolis: Universidade Federal de Santa Catarina, n. 20, p. 139-153, jun.-dez. 2008.

MELO, Luís Rocha. Historiografia audiovisual: a história do cinema escrita pelos filmes. Ars. São Paulo, v. 14, n. 28, p. 220-245, 2016.

PEIRANO, María Paz; GOBANTES, Catalina (Org). Chilefilms, el Hollywood criollo. Santiago: Cuarto Propio, 2014.

RUEDA, Jorge. La poesía popular de Héctor Meléndez en la revista Topaze. Revista

Iberoamericana. Pittsburgh: Universidade de Pittsburgh, vol. LXXVII, ns. 236-237, p. 731-747, juldez, 2011. 
SALINAS CAMPOS, Maximiliano. El teatro cómico de los treinta y las representaciones de Topaze y Juan Verdejo en los escenarios de Chile. Polis - Revista Latinoamericana, Santiago: Universidade de Los Lagos, vol. 5, n. 13, 2006.

SANTA CRUZ A., Eduardo. Entre huasos y rotos. Identidades en pantalla: el cine chileno en la década de los 40. In. BARRIL R., Claudia; SANTA CRUZ G., José (Org). El cine que se fue: 100 años de cine chileno. Santiago: Arcis, 2011.

El cine chileno y su discurso histórico sobre lo popular: apuntes para un análisis

histórico. Comunicación y Medios. Santiago: Universidade do Chile, n. 18. p. 57-69, 2008.

SANTA CRUZ G. José M. José Bohr y un cine ausente. In. BARRIL R., Claudia; SANTA CRUZ G., José (Org). El cine que se fue: 100 años de cine chileno. Santiago: Arcis, 2011.

Original recebido em: 19 de novembro de 2016

Aceito para publicação em: 19 de setembro de 2017

Fabián Núñez.

É professor adjunto do Departamento de Cinema e Vídeo da Universidade Federal Fluminense (UFF), desde 2009. Sua formação acadêmica foi inteiramente realizada na Universidade Federal Fluminense:

Bacharel em Comunicação Social (Habilitação em Cinema), em 2000; Mestre em Comunicação, Imagem e Informação, em 2003, e Doutor em Comunicação, em 2009. Foi credenciado ao Programa de Pós-Graduação em Comunicação (PPGCOM) da UFF, de 2010 a 2015. É membro da Associação Brasileira de Preservação Audiovisual (ABPA), fazendo parte de sua direção durante a gestão 20122014. Atua na organização do Cineclube Sala Escura, projeto de extensão vinculado ao LIA (Laboratório de Investigação Audiovisual), desde 2010. É pesquisador da Plataforma de Reflexão sobre o Audiovisual Latino-Americano (PRALA) e do Laboratório Universitário de Preservação Audiovisual (LUPA). Seus temas de interesse são: cinema latino-americano, cinema brasileiro, história do cinema, crítica cinematográfica e preservação audiovisual.

Esta obra está licenciada sob uma Licença Creative Commons. 